\title{
A DIMENSÃO TEMPO NA GESTÃO DAS EXPERIÊNCIAS DE LAZER EM PERÍODO DE PANDEMIA DA COVID-19 NO BRASIL
}

Recebido em: 08/08/2020

Aprovado em: 24/08/2020

Licença: @) (1) @

Ana Paula Evaristo Guizarde Teodoro1

Centro Universitário das Faculdades Metropolitanas Unidas (FMU)

São Paulo - SP - Brasil

Gustavo André Pereira de Brito2

Instituto Federal de Educação, Ciência e Tecnologia do Rio Grande do Norte (IFRN)

Natal - RN - Brasil

Laura Alice Rinaldi Camargo3

Universidade Federal do Paraná (UFPR)

Curitiba - PR - Brasil

Marcos Ruiz da Silva4

Centro Universitário Internacional (UNINTER)

Curitiba - PR - Brasil

Antonio Carlos Bramantes

Universidade de Brasília (UnB)

Brasília - DF - Brasil

RESUMO: Este estudo tem como objetivo analisar a dimensão tempo na gestão das experiências de lazer durante o distanciamento social por conta da pandemia COVID-19. A pesquisa, de natureza quali-quantitativa, do tipo descritiva, utilizou estudo de campo mediante a aplicação de um questionário on-line. A amostra foi composta de 2.278 brasileiros, acima de 18 anos. A análise dos dados foi realizada por meio de estatística

\footnotetext{
1 Doutora em Ciências da Motricidade, DEF/IB/UNESP Rio Claro/SP. Docente do Centro Universitário das Faculdades Metropolitanas Unidas (FMU). Pesquisadora do LAGEL - Laboratório de Gestão das Experiências de Lazer/GESPORTE/FEF-UnB, Brasília/DF.

2 Mestre em Educação Física, UNIMEP Piracicaba/SP. Docente do Instituto Federal de Educação, Ciência e Tecnologia do Rio Grande do Norte (IFRN). Pesquisador do LAGEL - Laboratório de Gestão das Experiências de Lazer/GESPORTE/FEF-UnB, Brasília/DF.

3 Doutora em Educação Física, área de concentração: Práticas Sociais, UEL/UEM Maringá/PR. Docente da Universidade Federal do Paraná (UFPR). Pesquisadora do LAGEL - Laboratório de Gestão das Experiências de Lazer/GESPORTE/FEF-UnB, Brasília/DF.

4 Doutor em Educação Física, área de concentração: Práticas Sociais, UEL/UEM Maringá/PR. Docente do Centro Universitário Internacional (UNINTER). Pesquisador do LAGEL - Laboratório de Gestão das Experiências de Lazer/GESPORTE/FEF-UnB, Brasília/DF.

5 Doutor em Filosofia na Faculdade de Desenvolvimento Humano/ The Penn State University/USA e Coordenador do LAGEL - Laboratório de Gestão das Experiências de Lazer/GESPORTE/FEF-UnB, Brasília/DF.
} 
descritiva e análise de conteúdo. Os resultados indicaram que a maioria dos respondentes teve tempo para as experiências de lazer, embora a maioria também tenha relatado que esse tempo diminuiu neste período. Entre os conteúdos culturais do lazer, os mais vivenciados de acordo com o tempo foram: os virtuais, os intelectuais e os manuais. Sugerem-se novos estudos que abordem esta temática, associando-os a outras dimensões do lazer.

PALAVRAS-CHAVE: Atividades de Lazer. Tempo. COVID-19.

\section{THE TIME DIMENSION IN THE MANAGEMENT OF LEISURE EXPERIENCES IN THE PANDEMIC PERIOD OF COVID-19 IN BRAZIL}

ABSTRACT: This study aims to analyze the time dimension in the management of leisure experiences during social distancing due to the COVID-19 pandemic. The research, of a quali-quantitative nature, descriptive type, used a field study approach through the application of an online questionnaire. The sample consisted of 2,278 Brazilians, over 18 years of age. Data analysis was performed through descriptive statistics and content analysis. Results indicated that the majority of respondents had time for leisure experiences, although most of them also reported that this time decreased during this period. Among the cultural contents of leisure, the most prevalent were: virtual, intellectuals and manuals experiences. Further studies are recommended to address this theme, by associating them with other dimensions of leisure.

KEYWORDS: Leisure Activities. Time. COVID-19.

\section{Introdução}

No final do ano de 2019, na cidade de Wuhan, na China, ocorreu um surto de uma doença respiratória causado pelo novo Coronavírus (SARS-CoV-2), denominada de COVID-19 (Coronavirus Disease 2019), na qual resultou em inúmeras mortes no mundo, inclusive, no Brasil (BRASIL, 2020a). Devido à rápida expansão da doença pelo mundo, a COVID-19 passou a ser considerada uma pandemia pela World Health Organization (WHO), tendo mais de 100 países atingidos de dezembro de 2019 a março de 2020 (WHO, 2020).

No Brasil, a pandemia teve contornos distintos de muitos outros países devido à ausência de coordenação política do governo federal com a maioria dos governos estaduais, recaindo sobre os municípios o ônus de arcar com as consequências dessa 
desarticulação. Mesmo assim, a partir de algumas iniciativas do setor público e da iniciativa privada, ações voltadas para prevenção do contágio da doença começaram a surgir, tais como medidas de distanciamento social, emissão de protocolos, boletins informativos, manuais e recomendações para a prevenção do contágio, entre outros.

Entre as medidas tomadas de enfrentamento à pandemia, o distanciamento social, adotado em outros países foi instaurado no Brasil por meio de decretos municipais e estaduais, determinando o fechamento de todo comércio de serviços não essenciais. Isso ocorreu após ser divulgada a Portaria n³56, do Ministério da Saúde, em 11 de março de 2020 (BRASIL, 2020b), que deliberou sobre a regulamentação e operacionalização do disposto na Lei $\mathrm{n}^{\mathrm{o}}$ 13.979, de 6 de fevereiro de 2020, estabelecendo as medidas para enfrentamento da emergência de saúde pública. A partir de então, as pessoas passaram a ficar mais dentro do lar, trabalhando em casa; as escolas foram fechadas temporariamente e somente os serviços essenciais nas áreas de saúde pública, alimentação, abastecimento, segurança e limpeza continuaram em funcionamento.

Com a recomendação de distanciamento social e um forte apelo para que todos permanecessem dentro de casa, as relações humanas mudaram, impactando diretamente no mundo das obrigações - notadamente o trabalho - assim como no mundo das nãoobrigações, aqui representado pelas atividades do âmbito do lazer de cada pessoa, o qual, neste estudo, foram expressas como experiências de lazer. O termo atividade remete a uma conotação mais quantitativa, enquanto que experiência, considera o componente da sua qualidade, a qual não se repete no tempo e no espaço; tornando-a sempre uma diferente da outra (BRAMANTE, 1998; BRAMANTE, 2020a).

Pensar o lazer no período de pandemia no qual as pessoas seguem em distanciamento social por vários meses, acaba sendo complexo e desafiador. Neste caso, há a necessidade de se compreender possíveis ressignificações para alguns conceitos 
como tempo e espaço, e, consequentemente, compreender a existência da construção de novas relações sociais, tendo em vista que, é no tempo e no espaço que os seres humanos estabelecem seus vínculos.

Como já mencionado por Requixa (1980, p.83) “o espaço doméstico é, por excelência, o espaço para o lazer”, e com o período de pandemia, essa afirmação passou a fazer mais sentido ainda, já que este espaço, além do tradicional ambiente de convivência familiar, torna-se também reconhecido como ambiente de trabalho (home office), de estudo (Ensino a Distância - EaD), de prática religiosa, além de espaço para vivenciar as experiências de lazer. Atrelado à ressignificação desse espaço, surge a necessidade de se compreender o tempo nesse novo contexto, os chamados "tempos sociais", aqueles destinados às dimensões acima descritas. De acordo com Padilha (2004, p. 218) "A vida em coletividade é regida pela articulação desses tempos sociais, enquanto cada indivíduo percebe e controla o tempo internamente".

Deste modo, as atividades e as experiências são dimensionadas por um tempo cronológico que organiza a vida ordinária em dias, semanas, meses e anos. Esta forma de planejar a vida cotidiana surge, principalmente, a partir da Revolução Industrial, com a emergência do capitalismo, quando se passou a exigir um maior controle do tempo. Assim, é bem demarcada a normatização da rotina do dia, da semana, do mês e do ano, na presença das mais diversas atividades da vida humana (SILVA, 2009).

A ordenação da vida subordinada à organização do tempo cronológico tem envolvido o ser humano para a noção de obrigação e não obrigação, atreladas à subjetividade qualitativa do modo de interpretar o tempo, tais como a noção de prazer, liberdade, felicidade, tédio e outras emoções. O modo de viver essa subjetividade qualitativa do tempo segue padrões dominantes de comportamento caracterizados por um todo coletivo, construídos por um saber comum, mantendo os indivíduos em convivência 
com os outros. No entanto, para Bicudo (2003, p. 21) “[...] essa mesmidade cessa no modo como cada um vive o tempo: angustiado, entediado pela sobra de tempo, asfixiado pela falta de tempo [...]”. Isso tudo, diferente das sociedades anteriores ao período da Revolução Industrial, onde a maioria das pessoas tinha maior autonomia em relação ao uso do seu tempo.

Com o distanciamento social imposto pela pandemia torna-se indispensável repensar o tempo para além dessas duas vertentes (forma integrada e forma compartimentalizada), considerando-se nuances de uma vertente intermediária, na qual, as relações específicas entre os tempos sociais, estão sendo mensuradas de formas diferentes. Nessa perspectiva, surge uma questão instigante: como pensar a gestão das experiências de lazer em uma sociedade moderna na qual o tempo da vida das pessoas é devidamente demarcado, sobretudo, em situação de distanciamento social?

A rotina cotidiana, condicionada a partir do significado atribuído ao tempo por determinadas sociedades, contribuiu para uma visão cartesiana da vida. Com essa situação, mantém-se em evidência, um indivíduo fragmentado nas ações e intenções. Este fato dificulta, de certa forma, a interpretação do fenômeno lazer, fora de parâmetros temporais tão marcantes. As funções estabelecidas pela categorização do tempo, exigem do indivíduo uma postura específica, como para as obrigações - seriedade - e para o tempo das não obrigações - relativa espontaneidade -, o que por sua vez pode inibir o indivíduo de viver na plenitude de sua vida, em todas as esferas sociais, dificultando a fluidez de sentimentos e sensações (SILVA, 2009).

Em situação de normalidade, os gestores de instituições públicas e privadas ligadas ao lazer, como clubes, parques, cinemas, teatros, museus, entre outras, são responsáveis por transmitir ou reforçar às pessoas, sentidos atribuídos à dimensão tempo. Isto acontece na forma como organizam uma programação, dimensionam o horário de 
funcionamento das atividades, entre outros fatores ligados à prática ou fruição das experiências de lazer. A excessiva formalização de um programa de lazer, tem potencial para provocar constrangimentos na forma como a pessoa pode se relacionar com a experiência proporcionada. A rigorosidade no controle do tempo para início e término de determinados programas e ou horários de funcionamento, por exemplo, pode provocar angústias (SILVA, 2009). Nessa direção, cabe ao gestor do lazer conhecer e reconhecer como as pessoas se relacionam com a dimensão tempo, nas experiências de lazer, para compreender como a gestão desses ambientes e programas pode influenciar na construção de sensações vividas nesse espaço de tempo. Isto tem a ver com a produção de diretrizes para executar os planejamentos que fornecem subsídios para a implementação de propostas no campo do lazer.

O conceito de lazer, mesmo após inúmeros debates na literatura, envolve uma série de discussões, correntes e teorias, porém, torna-se relevante destacar que neste estudo optou-se pelo recente conceito de Bramante (2020b, n.p.). Frente ao atual contexto da Pandemia COVID-19, esse autor apresentou a seguinte conceituação:

O lazer é uma dimensão humana privilegiada para poucos, que se traduz pela vivência lúdica possível, realizada dentro de um contexto marcado pela percepção de liberdade, na maioria das vezes, num tempo-espaço conquistado limitado, cuja qualidade está vinculada a um conjunto de conhecimentos, habilidades e atitudes adquiridas ao longo da vida. Trata-se de uma expressão genuína de vida, que valoriza a magia do inesperado, a subjetividade da experiência única, a riqueza dos sonhos e a gratuidade das relações humanas na plenitude da existência (BRAMANTE, 2020b, n.p.).

Foi utilizada também, a taxionomia proposta por Dumazedier (1973), corroborada e ampliada por Camargo (1986) e Schwartz (2003) dos conteúdos culturais do lazer. Mesmo com suas possíveis limitações e críticas devido a sua rigidez, essa classificação foi adotada para fins didáticos de entendimento dos respondentes da pesquisa em sua perspectiva de predominância da natureza da experiência de lazer.

Este estudo é um recorte de uma pesquisa mais abrangente intitulada " $\mathrm{O}$ impacto do distanciamento físico/social decorrente da COVID-19 nas experiências de lazer das

licere, Belo Horizonte, v.23, n.3, set/2020. 
pessoas". A presente pesquisa tem características diagnóstica e factual e retratou as circunstâncias que as pessoas estavam vivendo no momento em que a mesma foi realizada, dentro de um dos períodos mais agudos da pandemia COVID-19 no Brasil (maio de 2020), onde a maioria dos municípios, sobretudo os que têm maior população, encontrava-se em distanciamento social (AQUINO et al., 2020).

Baseado nesta nova rotina em casa que passou a fazer parte da vida dos brasileiros, assim como ocorreu em outros países, surgiram algumas inquietações: o tempo destinado às experiências de lazer aumentou? Diminuiu? Permaneceu o mesmo? Quais conteúdos culturais do lazer foram os mais vivenciados de acordo com o tempo investido? É possível estabelecer um equilíbrio entre uma das características essenciais do lazer, representada pela liberdade, com a obrigação de ficar em casa, característica do distanciamento social? Em termos de gestão, como as pessoas estão fazendo a autogestão de suas experiências de lazer, considerando sua autonomia para a tomada de decisões fundamentais sobre o que, quando e como fazer? Quais princípios das experiências de lazer em distanciamento social podem contribuir para a (re) orientação da ação profissional dos gestores do lazer?

Esta pesquisa se justifica, na medida em que poderá contribuir para ampliação das reflexões acerca da dimensão tempo para as experiências de lazer em período de pandemia da COVID-19 no Brasil. Para tanto, este estudo tem como objetivo analisar a dimensão tempo na gestão das experiências de lazer durante o distanciamento social por conta da pandemia COVID-19.

\section{Método}

Este estudo, de natureza quali-quantitativa, foi desenvolvido por meio de pesquisa descritiva, levantamento bibliográfico e estudo de campo. O presente estudo foi aprovado pelo Comitê de Ética e Pesquisas com Seres Humanos da Universidade Federal de 
Uberlândia/MG, sob parecer número: 4.081.860. Todos os princípios éticos foram assegurados aos participantes da pesquisa, de acordo com a Resolução 466/12, do Conselho Nacional de Saúde.

O estudo de campo foi realizado por meio da aplicação de um questionário online para uma amostra do tipo não probabilística, por conveniência, constituída de forma aleatória, composta por indivíduos que residem no território brasileiro, moradores nas cinco regiões do país. Para o cálculo de amostra mínima da pesquisa foi utilizado o Programa Gpower software. Utilizou-se como base a população brasileira estimada pelo Instituto Brasileiro de Geografia e Estatística (IBGE) em 2019, de 210.147.125 pessoas (IBGE, 2019) e o tamanho da amostra para desenho de Amostragem Aleatória Simples (AAS), proposto por Luiz e Magnanini (2000). A amostra mínima estimada foi de 1.067 pessoas, com nível de confiança de $95 \%$.

Como critérios de inclusão, foram selecionadas as respostas de indivíduos brasileiros, residentes no Brasil, com idade acima de 18 anos, que aceitaram participar da pesquisa por meio da anuência do Termo de Consentimento Livre e Esclarecido (TCLE). Foram excluídas as pessoas que não atenderam aos critérios de inclusão, as que não responderam de forma completa o questionário e aqueles que apresentaram as respostas em duplicidade.

O instrumento utilizado para a coleta de dados foi um questionário, desenvolvido por meio do aplicativo digital Microsoft Forms, com perguntas abertas e fechadas de múltipla escolha, o que possibilitou sua ampla disseminação on-line. Após a elaboração do questionário inicial, foi realizado o processo de validação por especialistas (PASQUALI, 2010), de modo que, cada uma das questões, tivesse maior clareza e relevância. Para tanto, foi criado um comitê com cinco especialistas no campo do lazer no Brasil, que avaliaram o questionário nos requisitos acima mencionados. Após o retorno 
A Dimensão Tempo na Gestão das Experiências de Lazer em Período de Pandemia da Covid-19 no Brasil Ana Paula Evaristo Guizarde Teodoro; Gustavo André Pereira de Brito; Laura Alice Rinaldi Camargo; Marcos Ruiz da Silva e Antonio Carlos Bramante

destas avaliações, o questionário foi ajustado conforme as recomendações dos especialistas, e assim, estabelecido o questionário definitivo. Entre as 53 questões definidas no instrumento da pesquisa "O impacto do distanciamento físico/social decorrente da COVID-19 nas experiências de lazer das pessoas”, em específico, foram utilizadas neste estudo, 04 perguntas sobre a dimensão tempo para o lazer, 08 sobre o tempo para as experiências de lazer ligadas aos conteúdos culturais do lazer e 09 envolvendo dados sociodemográficos.

Para a coleta de dados foi realizada uma ampla divulgação do link da pesquisa por meio de redes sociais, WhatsApp e e-mails a partir dos perfis dos pesquisadores. A divulgação da pesquisa também contou com o apoio de algumas associações ligadas à gestão, ao lazer e ao esporte. A coleta de dados foi realizada de 08/05/2020 a 31/05/2020.

Por se tratar de um estudo de caráter misto, foi necessária uma análise específica voltada tanto para os dados qualitativos como os quantitativos. Os dados quantitativos coletados foram analisados por meio de estatística descritiva. Os resultados foram apresentados em quadros por meio de números absolutos (n) e porcentagem (\%). Para a análise qualitativa foi utilizada a Análise de Conteúdo (BARDIN, 2016), na qual, foram seguidas as fases pré-análise, exploração do material e o tratamento dos resultados, culminando em unidades temáticas, agrupadas em categorias, definidas à posteriori.

\section{Resultados e Discussão}

Após realizadas as devidas análises, os resultados foram apresentados e discutidos por meio de quatro categorias: Categoria 1 - Caracterização da amostra, Categoria 2 Tempo e lazer durante a pandemia COVID-19, Categoria 3 - Quantidade de tempo em horas/minutos diários para as experiências de lazer durante a semana e nos finais de 
A Dimensão Tempo na Gestão das Experiências de Lazer em Período de Pandemia da Covid-19 no Brasil Ana Paula Evaristo Guizarde Teodoro; Gustavo André Pereira de Brito; Laura Alice Rinaldi Camargo; Marcos Ruiz da Silva e Antonio Carlos Bramante

semana e Categoria 4 - Distribuição do tempo para as experiências de lazer de acordo com cada conteúdo cultural do lazer.

A Categoria 1 - Caracterização da amostra, foi estabelecida com base na análise de nove questões envolvendo o perfil sociodemográfico dos participantes do estudo. A pesquisa contou com uma amostra válida de $n=2.278$ participantes, distribuída em 26 Estados e no Distrito Federal. O Quadro 1 possibilita observar, por Unidade da Federação (UF), a razão entre o número de respondentes e a população estimada (\%), o número de respondentes (n) e a população estimada por Estado em 2019 (n).

Quadro1: Número de respondentes e razão por população estimada.

\begin{tabular}{|c|c|c|c|c|}
\hline & UF & $\begin{array}{c}\text { Razão do número de } \\
\text { Respondentes por } \\
\text { População Estimada } \\
(\%) \\
\end{array}$ & $\begin{array}{l}\text { Respondentes } \\
\text { (n) }\end{array}$ & $\begin{array}{c}\text { População estimada } 2019 \\
\text { (IBGE, 2019) } \\
\text { (n) }\end{array}$ \\
\hline 1 & $\mathrm{AC}$ & 0,0009 & 8 & 881.935 \\
\hline 2 & $\mathrm{AL}$ & 0,0002 & 6 & 3.337 .357 \\
\hline 3 & $\mathrm{AM}$ & 0,0002 & 9 & 4.144 .597 \\
\hline 4 & $\mathrm{AP}$ & 0,0006 & 5 & 845.731 \\
\hline 5 & BA & 0,0003 & 51 & 14.873 .064 \\
\hline 6 & $\mathrm{CE}$ & 0,0005 & 50 & 9.132 .078 \\
\hline 7 & DF & 0,0069 & 209 & 3.015 .268 \\
\hline 8 & ES & 0,0008 & 32 & 4.018 .650 \\
\hline 9 & GO & 0,0004 & 25 & 7.018 .354 \\
\hline 10 & MA & 0,0005 & 34 & 7.075 .181 \\
\hline 11 & MG & 0,0006 & 134 & 21.168.791 \\
\hline 12 & MS & 0,0008 & 21 & 2.778 .986 \\
\hline 13 & MT & 0,0007 & 23 & 3.484 .466 \\
\hline 14 & PA & 0,0003 & 29 & 8.602 .865 \\
\hline 15 & PB & 0,0003 & 14 & 4.018 .127 \\
\hline 16 & $\mathrm{PE}$ & 0,0029 & 281 & 9.557 .071 \\
\hline 17 & PI & 0,0008 & 27 & 3.273 .227 \\
\hline 18 & PR & 0,0027 & 312 & 11.433 .957 \\
\hline 19 & $\mathrm{RJ}$ & 0,0007 & 115 & 17.264 .943 \\
\hline 20 & $\mathrm{RN}$ & 0,0026 & 91 & 3.506 .853 \\
\hline 21 & $\mathrm{RO}$ & 0,0010 & 18 & 1.777 .225 \\
\hline 22 & $\mathrm{RR}$ & 0,0048 & 29 & 605.761 \\
\hline 23 & $\mathrm{RS}$ & 0,0008 & 95 & 11.377 .239 \\
\hline 24 & $\mathrm{SC}$ & 0,0011 & 80 & 7.164 .788 \\
\hline 25 & SE & 0,0012 & 28 & 2.298 .696 \\
\hline 26 & SP & 0,0012 & 542 & 45.919 .049 \\
\hline
\end{tabular}


A Dimensão Tempo na Gestão das Experiências de Lazer em Período de Pandemia da Covid-19 no Brasil Ana Paula Evaristo Guizarde Teodoro; Gustavo André Pereira de Brito; Laura Alice Rinaldi Camargo;

Marcos Ruiz da Silva e Antonio Carlos Bramante

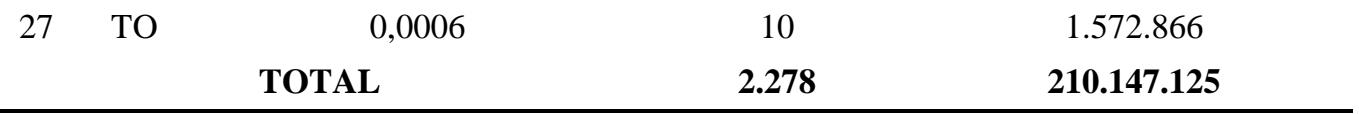

Fonte: Dados da pesquisa (2020).

A maioria dos respondentes da pesquisa é do Estado de São Paulo, seguido pelo Estado do Paraná, Distrito Federal, Pernambuco e Minas Gerais, todos com “n” acima de 100. Como a divulgação da pesquisa ocorreu de forma on-line, não foi possível identificar com exatidão o porquê destes resultados, porém, a hipótese mais provável é a de que além de ser São Paulo o Estado mais populoso, grande parte dos pesquisadores envolvidos neste estudo pertence a estes Estados, e, consequentemente, a divulgação pode ter sido maior nestas localidades.

Nos Estados Amazonas, Acre, Alagoas e Amapá este número ficou abaixo de 10. Possivelmente, se o período da coleta fosse prolongado, com um tempo maior para disseminação nos Estados com menor participação, estes números poderiam aumentar, havendo maior equilíbrio. Contudo, optou-se pelo encerramento do período da coleta antes dos Estados passarem a flexibilizar as medidas adotadas de distanciamento social por meio da suspensão dos decretos, ponto-chave associado aos objetivos deste estudo.

A média de idade foi de 39,8 anos, sendo a menor idade 18 anos e a maior idade relatada, 84 anos. Entre as faixas de idade, $51,4 \%$ da amostra possuem de 18 a 39 anos, $39,9 \%$ de 40 a 59 anos e $8,5 \%$ acima de 60 anos, sendo $0,2 \%$ os que não declararam a informação. A amostra do estudo foi composta de $61,4 \%$ de participantes que indicaram o gênero feminino, 38,4\% masculino e 0,2\% outros. Quanto à escolaridade, o Quadro 2 indica as respostas em porcentagem para este quesito. A maioria dos participantes da pesquisa, $42,4 \%$, possui pós-graduação completa.

licere, Belo Horizonte, v.23, n.3, set/2020. 
Quadro 2: Escolaridade.

\begin{tabular}{lc}
\hline Escolaridade & $\begin{array}{c}\text { Porcentagem } \\
(\mathbf{\%})\end{array}$ \\
\hline Sem instrução e menos de 1 ano de estudo & 0 \\
Ensino fundamental incompleto ou equivalente & 0,4 \\
Ensino fundamental completo ou equivalente & 0,6 \\
Ensino médio incompleto ou equivalente & 1,5 \\
Ensino médio completo ou equivalente & 5,3 \\
Ensino superior incompleto ou equivalente & 26,1 \\
Ensino superior completo ou equivalente & 23,7 \\
Pós-graduação completa & 42,4 \\
TOTAL & $\mathbf{1 0 0}$ \\
\hline
\end{tabular}

Fonte: Dados da pesquisa (2020).

Quando somadas as porcentagens das respostas "ensino superior completo" e “pós-graduação completa” o valor chega $66 \%$, o que aponta um alto grau de escolaridade entre a maioria dos respondentes da pesquisa, quando em 2019, segundo o IBGE (2020) somente $17,4 \%$ dos brasileiros com 25 anos ou mais tinha ensino superior completo.

O perfil de participantes com alto grau de escolaridade pode estar relacionado à escolha da divulgação da pesquisa on-line, pois, os pesquisadores enviaram o link por meio de suas redes sociais, WhatsApp e e-mails pessoais para seus amigos, colegas de trabalho, outros pesquisadores, além de associações ligadas à gestão, ao lazer e ao esporte. Esse movimento pode ter mobilizado um maior número de pessoas com perfis semelhantes aos seus em relação à alta escolarização dos respondentes, o que justificaria tal resultado.

Entre as questões sobre o perfil do respondente da pesquisa, uma delas perguntava se o mesmo estava trabalhando em home office, por meio de teletrabalho ou trabalho à distância ou trabalho remoto, no período da pandemia COVID-19. As respostas foram equilibradas, sendo que 50,7\% disseram estar trabalhando em home office no período da pandemia COVID-19 e 49,3\% relataram que não. O alto grau de contágio da COVID-19 levou muitas empresas a adotar diferentes rotinas de trabalho para seus colaboradores, entre elas, o trabalho em casa. O lar então, passou a ser o lugar de trabalho para a metade 
da amostra do presente estudo e isto pode ser um dos indicativos para os resultados encontrados e apresentados nas categorias de análise posteriores.

Para Gondim e Borges (2020) as pessoas que já estavam acostumadas com o home office e, de certa forma, já conheciam as ferramentas digitais, o processo de adaptação foi mais fácil, diferentemente daquelas que nunca tiveram contato com este tipo de possibilidade de trabalho e de repente, tiveram que se adaptar a esta nova condição. Para um número expressivo de pessoas, o home office pode se configurar um grande desafio ligado às dificuldades de se "encontrar a medida adequada da distribuição e execução de metas e prazos que concorrem com o tempo do convívio familiar, tarefas domésticas e atividades escolares” (LOSEKANN; MOURÃO, 2020 p.71), além das experiências de lazer.

Outra informação relevante foi com quem cada participante morava no período do distanciamento social por conta da pandemia COVID-19. Entre os respondentes, 28,6\% afirmaram morar com familiares, incluindo crianças de até 12 anos, 27,2\% com familiares, incluindo adolescentes a partir de 13 anos, 20,5\% apenas com cônjuge/namorado (a), 12\% com familiares, excluindo crianças e adolescentes e 10,1\% sozinho (a). Uma reduzida parcela de respondentes indicou morar com amigos, $1,4 \%$, com animais de estimação, $0,1 \%$ e outros, $0,1 \%$.

Entre os participantes que responderam que moravam com alguém (89,9\% do total da amostra) no período de distanciamento social por conta da pandemia COVID-19, $61,9 \%$, disseram que as pessoas que moravam com ele não dependiam de seus cuidados, com a maioria $(67,7 \%)$, indicando que se tratava de filho (a), enteado (a), sobrinho (a) ou afilhado (a); 21,3\% pai, mãe, sogro (a) ou tio (a); 3,4\% cônjuge, companheiro (a) ou namorado (a); 2,9\% avô ou avó; 2,6\% irmã (o), primo (a) ou amigo (a); 1,3\% neto (a); $0,7 \%$ animais de estimação e $0,1 \%$ nada declarou. 
Entre os participantes da pesquisa que declararam morar com pessoas que dependiam deles $(38,1 \%)$, por intermédio da resposta em uma escala do tipo Likert (“não dependência", “2”, “3”, “4” a "total dependência”), 41,5\% afirmaram que as pessoas que moravam com eles eram totalmente dependentes e $24 \%=3$. Na sequência, $14,5 \%=4$ e $14 \%=2$. Seis por cento apontaram para "não dependência". Mesmo sendo em menor porcentagem os que apontaram que moravam com pessoas que dependiam de seus cuidados, essas pessoas possuíam total dependência, referindo-se principalmente, a filho (a), enteado (a), sobrinho (a) ou afilhado (a).

Os resultados apresentados na Categoria 2 - Tempo e lazer durante a pandemia COVID-19, permitiram interpretar como as pessoas compreenderam seu tempo conquistado para as experiências de lazer, em situação de distanciamento social, devido a pandemia COVID-19. Além disso, foi possível evidenciar se o tempo para o lazer aumentou, diminuiu ou permaneceu o mesmo neste período.

A maioria dos participantes da pesquisa (79\%) afirmou dispor de tempo para vivenciar o lazer no período de distanciamento social provocado pela pandemia COVID19. O restante, $21 \%$, informaram que não tiveram tempo para vivenciar as experiências de lazer neste período.

Entre os participantes da pesquisa com tempo para o lazer, $54,2 \%$ dos respondentes compreenderam que o tempo para as experiências de lazer durante o período de distanciamento social diminuiu, comparado ao período anterior à pandemia COVID19. Para $32,3 \%$ dos participantes esse tempo aumentou, enquanto para $13,5 \%$ esse tempo permaneceu o mesmo.

Os dados descritos no Quadro 3, são referentes ao cruzamento das respostas dos participantes da pesquisa que afirmaram contar com tempo para as experiências de lazer e os que não tiveram tempo para as experiências de lazer. 
Quadro 3: Experiências de lazer antes do distanciamento social com o momento atual entre os respondentes com tempo e sem tempo para as experiências de lazer.

\begin{tabular}{c|c|c|c|c}
\hline $\begin{array}{c}\text { Experiências de } \\
\text { lazer antes do } \\
\text { distanciamento } \\
\text { social com o } \\
\text { momento atual }\end{array}$ & $\begin{array}{c}\text { Respondentes } \\
\text { com tempo (n) }\end{array}$ & $\begin{array}{c}\text { Respondentes } \\
\text { com tempo (\%) }\end{array}$ & $\begin{array}{c}\text { Respondentes } \\
\text { sem } \\
\text { tempo (n) }\end{array}$ & $\begin{array}{c}\text { Respondentes } \\
\text { sem } \\
\text { tempo (\%) }\end{array}$ \\
\hline $\begin{array}{c}\text { Aumentou muito } \\
\text { Aumentou }\end{array}$ & 153 & 8,6 & 3 & 0.6 \\
Permaneceu a & 425 & 23,7 & 19 & 4,0 \\
mesma & 245 & 13,5 & 44 & 9,3 \\
Diminuiu & 529 & 29,2 & & 21,6 \\
Diminuiu muito & 449 & 25,0 & 103 & 64,5 \\
TOTAL & $\mathbf{1 8 0 1}$ & $\mathbf{1 0 0}$ & 308 & $\mathbf{1 0 0}$ \\
\hline
\end{tabular}

Fonte: Dados da pesquisa (2020).

A diminuição do tempo para as experiências de lazer no período de distanciamento social pode estar relacionada à alguns indícios, como a suspensão das aulas presenciais nas escolas por conta da pandemia COVID-19, onde muitas crianças e adolescentes passaram a assistir as aulas remotamente, em casa. Muitos pais e mães que tiveram no período de distanciamento social em home office, passaram a conviver em tempo integral com seus filhos, tendo que conciliar diferentes tarefas no mesmo espaço físico. Além disso, com o fechamento de parques, shoppings e outros espaços ligados ao entretenimento, as opções de vivências no âmbito do lazer também ficaram restritas ao espaço físico do lar. Isso tudo pode ter provocado sobrecargas ligadas às obrigações e justificar esta diminuição do tempo para o lazer.

Outra hipótese que pode ser levantada é de que as mulheres são as principais responsáveis pelas atividades relacionadas aos cuidados domésticos e familiares, nas quais dedicam $73 \%$ a mais de horas com os cuidados de pessoas e/ou afazeres domésticos do que os homens (OLIVEIRA, 2020). Como a amostra do presente estudo é composta, em sua maioria, de mulheres, este fator pode ser mais um argumento sobre os possíveis resultados apresentados. 
Ainda pode ser incluída como uma justificativa para esses resultados, a falta de moradias adequadas para a prática das experiências de lazer. Mesmo a amostra do presente estudo ser constituída de uma maioria com pós-graduação completa, o que pode indicar um rendimento salarial acima da média da população brasileira, ainda assim, para uma considerável parcela de pessoas no Brasil, as desfavoráveis condições de moradia podem representar dificuldades no acesso ao lazer. Entre as limitações ligadas às moradias estão, a falta de espaço físico para as experiências de lazer, a fraca conexão de internet, a renda insuficiente para as necessidades básicas, entre outras (COUTO; COUTO; CRUZ, 2020).

Considerando todos os resultados do cruzamento destacado no Quadro 3, foi possível identificar um número expressivo de pessoas cujas respostas indicaram compreender que houve alteração no tempo cronológico conquistado para o lazer $(86,5 \%)$. Este dado oferece indicativos de que a situação do distanciamento social provocou mudanças significativas na compreensão das pessoas quanto ao tempo conquistado para as experiências de lazer.

Os dados do Quadro 03 indicam uma provável dificuldade entre os respondentes em precisar seu tempo disponível para o lazer, seja para mais ou para menos tempo. Esse resultado apresenta indicativos de uma relativa confusão para a determinação das horas diárias vivenciadas no lazer.

Os indicativos das respostas destas questões, sobre a dificuldade que as pessoas possuem em estabelecer o tempo dispendido com lazer, confirmam o que diz Pronovost (2011), quando o autor sustenta que há uma pressão social, culturalmente construída, que atribuiu ao tempo valor e legitimidade, na qual leva as pessoas a declararem não possuírem tempo para o lazer. Disto, resulta a ideia de tempo como um recurso que não 
pode ser desperdiçado, controlado, e desta forma, com o uso extensivo de relógios e calendários, com finalidade de dar precisão aos compromissos diários.

A dificuldade em se estabelecer o tempo conquistado para o lazer foi observada no grupo que apontou, na primeira questão, se houve tempo ou não para as experiências de lazer no período de distanciamento social por conta da pandemia COVID-19. Entre alguns dos fatores que podem contribuir para essa dificuldade estão as próprias vivências em si. Alguns respondentes podem ter ficado na dúvida se determinada experiência realizada pode ser considerada uma vivência do âmbito do lazer ou não.

Essa dificuldade pode ser ampliada pelo fato da permeabilidade que a vida se configura dentro de casa - o trabalho, as obrigações domésticas, o lazer, a alimentação, ocorrerem transpassando o rigor do tempo da vida ordinária, exterior à vida em distanciamento social. Isto porque, a vida cotidiana em distanciamento social, em relativa reclusão, não conta com características muito marcadas, como o cumprimento da rotina de ir ao trabalho, de ir para a escola, por exemplo.

O cenário que se constitui com as experiências de lazer em situação de distanciamento social, ao qual, os participantes da pesquisa permaneceram reclusos em suas casas, desenvolvendo todas as atividades essenciais para sua subsistência, inclusive as laborais, indica considerar o que sugere Almeida (2005), quando o autor fala que é necessário pensar teorias para se discutir o lazer e transcender o discurso sobre a categorização de tempo livre, ou mesmo, tempo disponível.

Outro aspecto que merece atenção em relação à possíveis alterações da percepção de tempo para as experiências de lazer em período de distanciamento social pode ser o grau de autonomia que as pessoas possuem para organizar suas vidas, de forma a dar vazão relativamente equilibrada às diferentes dimensões sociais, inclusive ao lazer. Neste caso, a autonomia está ligada à ideia de autogestão, como práticas que refletem aquilo 
que é produzido por si mesmo (BATISTELA; MONTEIRO, 2014). No entanto, essa consideração depende de fatores como, o nível de conhecimento e o grau de domínio socioafetivo que cada um possui (BIZARRO, 2004). Desta forma, quanto menor o grau de autogestão que uma pessoa tem para autorregular sua vida, consequentemente, menor autonomia, e maior dificuldade para administrar a vida, dentro da dimensão temporalcronológica, especialmente em tempos de excepcionalidade, como da pandemia.

Para apresentar os dados da Categoria 3 - Quantidade de tempo em horas/minutos diários para as experiências de lazer durante a semana e nos finais de semana, foram levadas em consideração as análises de duas questões do instrumento de pesquisa. A primeira delas relativa ao tempo em horas/minutos diários para o lazer de segunda a sexta-feira e a segunda, referente ao tempo em horas/minutos diários para o lazer aos sábados e domingos.

Para a primeira questão, "horas/minutos diários para o lazer de segunda a sextafeira", dos 2.278 participantes da pesquisa, $87 \%$ foram considerados com respostas válidas, enquanto que, para a segunda questão, "horas/minutos diários para o lazer aos sábados e domingos", $86 \%$ foram consideradas válidas. Foram estabelecidas como respostas válidas para ambas as questões, os retornos indicados pelos participantes, de até 16 horas diárias. Esse valor estipulado, corrobora com Muné (1980) que considera 08 horas diárias, dentre as 24 horas disponíveis no dia, para o ajuste do tempo psicobiológico. O tempo psicobiológico é utilizado para suprir as necessidades essenciais como, o sono, a alimentação, as necessidades fisiológicas, entre outras.

Os demais participantes, ou seja, os $13 \%$ restantes, para a questão de "horas/minutos para o lazer de segunda a sexta-feira", e os 14\% para a questão "horas/minutos para o lazer aos sábados e domingos" deixaram de responder, responderam zero horas, nenhuma hora, acima de 16 horas, ou ainda, responderam frases 
sem sentido com a pergunta realizada, sendo impossível qualquer contabilização. Portanto, foram desconsiderados para a discussão desta categoria e esses respondentes desconsiderados, foram tratados como valores omissos.

Quando analisada a média diária em horas disponíveis para o lazer, foi evidenciada uma média de 03 horas e 22 minutos de segunda a sexta-feira e de 05 horas e 08 minutos aos finais de semana. Considerando essas médias de tempo descritas durante a semana e aos finais de semana - sábado e domingo, pode-se observar que mesmo com o distanciamento social, e a transferência do trabalho, dos estudos e da escola para o ambiente da casa, o tempo conquistado para o lazer aos finais de semana, continua sendo significativamente maior. Os resultados demonstram a manutenção da organização e frequência dessas horas no espaço da rotina cotidiana, que permanece igual ao período anterior ao distanciamento social, em relação aos dias úteis e de finais de semana.

A análise desta categoria nos apresenta que $43 \%$ dos respondentes tiveram tempo para as experiências de lazer, de segunda a sexta, até 02 horas diárias, contrapondo com $21 \%$ aos sábados e domingos. Entre a disponibilidade acima de 02 horas até 04 horas diárias, o percentual se mantém em $25 \%$ tanto para os dias de semana, quanto para os sábados e domingos. Em relação ao percentual de respondentes que disseram ter mais de 04 horas até 06 horas diárias, durante a semana, esse número representa 1\% para os dias de semana e $18 \%$ para os sábados e domingos.

Ao longo dos anos ocorreram algumas pesquisas sobre orçamento-tempo e representatividade do lazer na sociedade em diferentes países (REQUIXA; CAMARGO, 1989; CUSHMAN; VEAL; ZUZANEK, 2007; FISHER; ROBINSON, 2010; PRONOVOST, 2011; UVINHA et al. 2017), porém, este número é reduzido quando comparado ao número de pesquisas relacionadas às correntes teóricas sobre o lazer, por exemplo. Isso ocorre principalmente pelas dificuldades encontradas ao realizar este tipo 
de pesquisa, pois, para a sua execução, o investimento financeiro é alto, exige complexo tratamento de dados e demanda um período longo para sua efetivação (CAMARGO, 1986).

Camargo (1986) apresentou em seu livro "O que é lazer", os dados de uma pesquisa realizada no Rio de Janeiro em 1973, cuja média de tempo para o lazer nesta década era de 27 a 30 horas semanais, o que corresponde a uma média de 04 horas diárias. Pronovost (2011) ilustra dados de uma pesquisa longitudinal realizada no Canadá onde as médias semanais para o lazer foi de 36,1 horas em 1986; 38 horas em 1992; 38,5 horas em 1998 e 36,6 horas em 2005. Ao realizar um cálculo médio para estabelecer a quantidade de horas diárias, na pesquisa de Pronovost, encontra-se a média de 5,3 horas por dia para as vivências do âmbito do lazer.

Os dados da pesquisa de Bridi; Bohler e Zanoni (2020) "Trabalho remoto/home office no contexto da pandemia COVID-19”, demonstram um aumento de dias e horas no ritmo de trabalho dos entrevistados, com tendência a execução de atividades laborais por mais de 8 horas diárias. $\mathrm{O}$ acréscimo do tempo de trabalho, é explicado pela extensão das jornadas, da conexão 24 horas por dia; das demandas a qualquer tempo, a dificuldade da desconexão e a ampliação das tarefas realizadas no mesmo ambiente, como os afazeres domésticos, o cuidado com os filhos e o trabalho profissional, tudo sendo feito ao mesmo tempo. Tal estudo, constata os impactos do home office na vida profissional e pessoal dos entrevistados, e reforça a diminuição do tempo médio das horas de lazer dos respondentes da presente pesquisa, se comparadas com estudos já apontados.

O surgimento da pandemia e a necessidade do distanciamento social, impulsionaram os avanços tecnológicos do home office e do ensino remoto. Um número significativo de respondentes passou a desenvolver as suas atividades profissionais e de 
estudos dentro de casa, tornando-a um espaço de pluriatividade, ou seja, a coexistência no mesmo tempo e no mesmo espaço de atividades paralelas e interligadas.

Em relação as mulheres, como citado na Categoria 2, cabe ressaltar uma situação ainda comum: a dupla (ou múltiplas) jornada de trabalho a que muitas estão submetidas, alternando os afazeres profissionais e domésticos, o que pode reduzir, substancialmente, o tempo dedicado ao lazer. Os limites entre lazer e trabalho estão cada vez mais tênues (GOMES, 2014), e o surgimento da pandemia COVID-19, pode ter aproximado ainda mais este limite, avançando em alguns anos uma nova possibilidade de organização e percepção do tempo destinado ao lazer.

Após as análises das respostas para a Categoria 4 - Distribuição do tempo para as experiências de lazer de acordo com cada conteúdo cultural do lazer, foi evidenciada a seguinte distribuição do tempo, por dia, para cada um dos conteúdos culturais do lazer, conforme ilustrado do Quadro 4.

Quadro 4: Horas diárias por conteúdo cultural do lazer.

\begin{tabular}{c|c}
\hline Conteúdos culturais do lazer & Média em horas diárias \\
\hline virtual & $01 \mathrm{~h} 59 \mathrm{~min}$ \\
intelectual & $01 \mathrm{~h} 15 \mathrm{~min}$ \\
manual & $01 \mathrm{~h} 12 \mathrm{~min}$ \\
artístico & $59 \mathrm{~min}$ \\
turístico & $53 \mathrm{~min}$ \\
físico-esportivo & $44 \mathrm{~min}$ \\
social & $43 \mathrm{~min}$ \\
\hline
\end{tabular}

Fonte: Dados da pesquisa (2020).

Observa-se uma dissonância entre a Categoria 3 e a Categoria 4 em termos numéricos de média diária para o lazer. Em se tratando do tempo destinado às experiências de lazer por conteúdo cultural, é importante destacar que os respondentes poderiam escolher entre uma ou mais das sete opções.

Ao observar as respostas apresentadas, pode-se notar que os dados confirmaram o quanto as tecnologias e o ambiente virtual vêm promovendo alterações nas dinâmicas sociais nas duas últimas décadas, tendo se mantido mais aparente no período do 
distanciamento social estudado, uma vez que as pessoas se encontravam confinadas em seus lares como medida preventiva contra a doença. Neste sentido, a casa não é mais um espaço isolado do mundo, as pessoas estão o tempo todo conectadas com o ambiente externo e, consequentemente, lidam com as ferramentas tecnológicas com maior facilidade. Aliado a isso, a alta demanda pelas atividades ligadas às tecnologias virtuais pode ser atribuída também à utilização das mídias sociais digitais, ou seja, os meios que determinada rede social utiliza para realizar sua comunicação.

Nesse contexto, pode-se destacar no período da pandemia COVID-19 um aumento expressivo na utilização das redes sociais on-line, como, Facebook, Youtube, Instagram, Tik Tok, WhatsApp, entre outras, que aproximam pessoas. Um exemplo foi o crescimento de $70 \%$ nas lives no Instagram, somente no mês de março de 2020 (DIONISIO, 2020). Contudo, o fato de o tempo destinado ao conteúdo virtual do lazer aparecer de forma mais expressiva, não representa, necessariamente, a busca pela promoção de impactos interacionais, por meios que facilitam a relação têmporo-espacial (SCHWARTZ, 2003). Isto, por haver uma subjetividade nas escolhas dos indivíduos com interesses específicos que os impulsionam para a prática de uma ou de outra atividade (MARCELLINO, 2002), como é o caso, das lives de artistas renomados em plataformas como Instagram, Youtube ou Facebook. Essas plataformas, no período de distanciamento social surgiram como um novo caminho para a classe artística que, ao mesmo tempo em que entretêm os telespectadores, ganha espaço junto aos patrocinadores e, ainda, arrecadam donativos para as causas sociais (SOUSA JÚNIOR et al., 2020).

Este fato incentivou o aumento das publicações na rede por parte de quem teve conteúdo e impulsionou de forma instantânea, as performances (COUTO; COUTO; CRUZ, 2020), que pela taxionomia estudada podem ser classificadas como conteúdo artístico do lazer, além das transmissões on-line de exercícios físicos (RAIOL, 2020), que 
podem ser classificadas como conteúdo físico-esportivo do lazer. Essas considerações podem inferir que o considerável tempo disponibilizado às vivências ligadas ao conteúdo virtual do lazer, está diretamente ligado a confusão relacionada a classificação das atividades (PRONOVOST, 2011), já que, mesmo quando a motivação para a escolha da atividade foi a estética, o movimento ou o exercício físico, que em tese, deveriam estar associados a outros conteúdos culturais do lazer; o respondente pode ter assinalado como conteúdo virtual do lazer, pela utilização do meio digital para usufruir de tais práticas.

Um tempo também expressivo, de 01 hora e 15 minutos por dia, foi destinado ao conteúdo intelectual do lazer. Entre as experiências que englobam este conteúdo estão aquelas ligadas ao raciocínio, à sensibilidade individual, à busca por informações objetivas, por práticas que possibilitem à aquisição de conhecimento e que possuem caráter cognitivo e não estético. Este resultado pode estar relacionado a dois aspectos, o primeiro, ao próprio local da prática, ou seja, a casa, propício para diversas atividades intelectuais como: leituras, jogos de xadrez, de dama, dominó, sudoku, enigmas, caçapalavras, charadas, desafios e exercícios de lógica, cursos e palestras (não profissionais), colecionismo, entre outros. Corroborando com esse pensamento, Campos (2020), em pesquisa realizada entre abril e maio de 2020 , por conveniência, afirma que a casa é um espaço propício para a prática da leitura. Entre os respondentes da pesquisa de Campos (2020), 90,6\% afirmaram ter realizado leituras no período da pandemia COVID-19, destes, $81,3 \%$ leram livros e desses, $80,6 \%$ realizaram as leituras de forma digital.

O segundo aspecto para o conteúdo intelectual ter compreendido uma quantidade de tempo considerável, pode ter relação com o perfil da amostra. Mesmo que de forma não intencional, tendo em vista que ela foi constituída, em grande parte, por pessoas com alto grau de escolaridade/poder econômico. Sabe-se que o fator econômico e a oportunidade de acesso à educação formal podem ser decisivos frente a diminuição das 
barreiras para o lazer, possibilitando maior conhecimento e ampliação das opções, das escolhas das experiências, o que contribui para maior distribuição do tempo para o lazer (MARCELLINO, 2002; PINTO, 2008; PACHECO, 2010; UVINHA, 2017).

O conteúdo manual do lazer, que apareceu na pesquisa com o tempo de 01 hora e 12 minutos diários para as vivências dessas experiências, é aquele que envolve o tato, com motivação na manipulação, quer seja de objetos ou da natureza para transformá-los. Frequentemente, este conteúdo é confundido como um hobby, outras vezes, confundido com o trabalho e com as atividades artísticas.

Nesse caso, vale destacar que a cultura da atividade de característica manual já foi considerada um aspecto representativo da cultura popular (DUMAZEDIER, 1980), no Brasil, e em estudos com grupos específicos de idosos, a representatividade de atividades manuais, sobretudo, aquelas desenvolvidas em casa, como: crochê, tricô, costura, pintura e bordado, ainda é muito recorrente (ARGIMON et al., 2004; BALSAN, 2006; RICARDO et al., 2013).

O tempo destinado ao conteúdo artístico do lazer foi de 59 minutos diários. Representado pelo imaginário, pelas imagens, pela busca da arte e do prazer que as diversas linguagens artísticas propiciam, as emoções e os sentimentos. Este conteúdo pode ser compreendido como local de contemplação, como as idas à museus, às exposições, às feiras, à cinemas, à teatros, entre outros, mas também, experiências ligadas à produção de arte, como a composição musical, das falas e da escrita, as dramatizações, entre outras (MARCELLINO, 2002; MELO; ALVES JÚNIOR, 2003; SCHWARTZ et al., 2016).

O tempo destinado ao conteúdo artístico, declarado pelos participantes do estudo, pode ter sido subdimensionado, se for levado em consideração que, para o senso comum, 
para usufruir deste conteúdo cultural do lazer seria necessário deixar de seguir as medidas de distanciamento social impostas no período em estudo.

Além disso, pode ter ocorrido uma dificuldade na determinação em horas para este conteúdo, por parte dos participantes da pesquisa, quanto ao interesse que impulsiona sua escolha, levando-os a responder conteúdo virtual do lazer em detrimento ao conteúdo artístico do lazer, pois, no período da pesquisa houve maior valorização da cultura e do uso do tempo diário com atividades de arte, por meio de diversas redes sociais on-line (CALABRE, 2020), sobretudo nas lives de artistas renomados, como no "Festival Música em Casa - Live Show” (SOUSA JÚNIOR et al., 2020).

O conteúdo turístico do lazer, aquele que engloba a quebra da rotina espacial, a busca por novas paisagens, a possibilidade de conhecer novas pessoas e lugares, novos costumes, como ocorre em viagens (MARCELLINO, 2002), obteve 53 minutos de vivência diária como resposta. Neste caso, é necessário ponderar com algumas observações: a primeira, relacionada ao tempo gasto na prática, tendo em vista que para as vivências neste conteúdo, normalmente, o tempo é bem superior ao de outros conteúdos, pois depende do deslocamento e da quantidade de atrativos locais. Geralmente, este tipo de experiência demanda um tempo maior, seja para se fazer uma viagem, para conhecer outra cidade ou para visitar um parque em uma localidade mais distante (MEDLIK; LOCKWOOD, 2003).

A segunda observação é que, no conteúdo turístico do lazer, as vivências são dependentes de situações como, as oscilações na taxa de câmbio, as flutuações sazonais da demanda, a instabilidade política, o terrorismo, os riscos meteorológicos, geológicos, epidêmicos e pandêmicos que comprometem a saúde pública, entre outros (BENI, 2020). Tudo isso agravado pelas Portarias Ministeriais, que determinou o fechamento das fronteiras brasileiras, tanto aéreas quanto terrestres, para pessoas de outras 
nacionalidades, paralisando muitas viagens, sugerindo que esse tempo pode ter sido menor.

O tempo distribuído para as vivências relacionadas ao conteúdo físico-esportivo do lazer, que estão associadas às práticas corporais de movimento e esportivas, foi de 44 minutos diários. Em períodos anteriores ao distanciamento social, essas atividades são as mais vivenciadas entre os conteúdos culturais do lazer, principalmente pelo fato de serem as mais difundidas pelos meios de comunicação (MELO; ALVES JUNIOR, 2003; MELO, 2004; UVINHA et al.,2017). Infere-se que, por apresentar atividades que estão sendo transmitidas por profissionais de Educação Física para orientação dos exercícios pelos meios digitais, como as videochamadas ou similares (RAIOL, 2020), mesmo que sua motivação principal tenha sido o movimento ou o exercício físico, essas vivências tenham sido classificadas, pelos respondentes, como conteúdo virtual.

Outra hipótese para o conteúdo físico-esportivo não apresentar um tempo mais expressivo pode estar relacionada com o fechamento dos parques e das academias, esse último, frequentado no Brasil por 9,6 milhões de pessoas em 2017 (CARVALHO; SILVA; OLIVEIRA, 2020). Esse novo contexto pode ter provocado uma diminuição destas práticas, tendo em vista que, mesmo as pessoas ativas fisicamente tiveram que adaptar o espaço físico da casa para tentar continuar se mantendo ativas. No entanto, se este espaço for limitado ou se a modalidade preferida exigir equipamentos específicos que não possam ser adaptados/comprados, a adesão à essa prática acaba sendo prejudicada, indicando que, muitas vezes, essas práticas tiveram que ser suspensas (RAIOL, 2020). Apesar disso, esses 44 minutos diários de prática, representa um tempo satisfatório em se tratando de exercícios físicos e práticas esportivas, se forem consideradas as diretrizes do American College of Sports Medicine (ACSM), as quais orientam que adultos realizem 30 minutos ou mais atividade física moderada, pelo menos 
A Dimensão Tempo na Gestão das Experiências de Lazer em Período de Pandemia da Covid-19 no Brasil Ana Paula Evaristo Guizarde Teodoro; Gustavo André Pereira de Brito; Laura Alice Rinaldi Camargo; Marcos Ruiz da Silva e Antonio Carlos Bramante

cinco vezes por semana ou 20 minutos de atividade física vigorosa, três vezes por semana (ACSM, 2011).

O conteúdo social do lazer, caracterizado pela busca do envolvimento com grupos, pela socialização, pelo encontro, o convívio social, o contato com o outro, em festas, nos restaurantes, nos bares, nos clubes ou até mesmo por meio da interação nas redes sociais (MARCELLINO, 2002; MELO, 2004; SCHWARTZ et al., 2016), ficou na última posição em relação à quantidade de tempo despendido, com 43 minutos diários. Constatou-se que, pelo fato do contato social não estar ocorrendo de forma presencial, os respondentes podem ter tido dificuldades quanto à escolha deste conteúdo, mesmo que nesse período de distanciamento social estejam sendo desenvolvidas muitas redes de relacionamentos on-line, quer seja por meio dos telefones, das câmeras, por áudios ou vídeos (TOMAÉL; ALCARÁ; DI CHIARA, 2005).

De modo geral, os dados expressos em horas diárias para cada conteúdo cultural do lazer não significam que a quantidade de tempo distribuído para as diversas experiências seja insatisfatória pois, para cada conteúdo cultural do lazer será necessária uma análise específica. Além disso, é relevante destacar que a ordem em relação à quantidade de horas semanais vivenciadas não indica a preferência pelo conteúdo em si, apenas representa uma média quantificável dentro do tempo que cada um disponibilizou para o lazer, mesmo compreendendo que há uma tendência a subestimar o tempo para essas experiências.

Ao analisar a questão relativa ao detalhamento das práticas e do tempo gasto em cada uma delas, no período de distanciamento social, referente a questão aberta do instrumento, torna-se relevante esclarecer que apenas 17\% da amostra optou por detalhar suas práticas. Além das práticas, os dados permitiram a quantificação média em horas/minutos semanais por atividades. Apenas para fins de unificação do entendimento 
dentro da taxonomia adotada, essas atividades foram então classificadas, conforme demonstrado a seguir:

- Conteúdo virtual (lives, 03h00min; videogame, 02h30min; pesquisas na web, 02h00min e jogos virtuais, 01h00min);

- Conteúdo intelectual (leitura, 10h30min; escrita, 08h05min e jogos cognitivos, 01h00min);

- Conteúdo manual (culinária, 09h35min; colecionismo, 08h00min; decoração, 07h00min; jardinagem, 04h35min; pintura, 03h00min; artesanato, costura e bijuteria, 01h00min);

- Conteúdo artístico (assistir séries, 09h25min; ouvir música, 09h20min; assistir filmes, 08h35min; assistir TV, 03h10min; ver fotografia, 02h30min; tocar instrumentos musicais, 02h00min; assistir vídeos, 01h00min);

- Conteúdo turístico (passeio ao campo e passeio à praia, 05h00min);

- Conteúdo físico-esportivo (meditação, zumba e pesca, 07h00min; esportes, 06h00min; ciclismo, 05h35min; exercícios físicos, 05h30min; dança, 05h00min; musculação, 04h55min; corrida, 03h45min; natação, 03h30min; alongamento, 03h20min; caminhada, 03h15min; jiu-jitsu, 03h00min; andar de moto, 02h20min; yoga, futebol e voleibol, 02h00min); e

- Conteúdo social (conversar com familiares, 10h30; conversar com amigos, 08h00min; sexo, 05h00min; namorar, 04h30min e redes sociais, 04h05min).

Após a análise desses dados, verificou-se que mesmo com os decretos estaduais e municipais de distanciamento social, alguns respondentes não os seguiram em sua totalidade, já que apareceram respostas como, o futebol, o voleibol, andar de moto, passear ao campo, passear na praia, o ciclismo, a pesca, a corrida, entre outras. 
Ainda nesta questão, um expressivo percentual dos 389 respondentes desse estudo (70,6\%), descreveu práticas ligadas às obrigações, segundo Dumazedier (1973), ao invés de relatar suas vivências relacionadas ao lazer. Destes, 38\%, destacaram atividades ligadas a obrigações familiares (cuidados domésticos, cuidados com filhos, cuidados com animais, cuidados pessoais); 20\%, ligadas as obrigações profissionais (trabalho e estudo); 7,2\%, ligadas aos cuidados fisiológicos (comer e dormir); 4,4\%, ligadas as obrigações religiosas (práticas religiosas como fazer orações/preces e reuniões religiosas) e $1 \%$ ligadas as obrigações sociais (aniversários, mesmo que virtual). Dessa maneira, foi possível identificar que há uma falta de clareza no tocante a diferença entre o trabalho, as demais obrigações sociais e as práticas do âmbito do lazer.

Este fato pode ter ocorrido por conta do "senso comum" atribuído à identificação do lazer estar ligado, apenas, ao elemento prazer, como se as obrigações não pudessem ser prazerosas (MELO; ALVES JÚNIOR, 2003). Portanto, o que se observou, foi a falta do entendimento mais amplo de que o lazer é constituído a partir dos quatro elementos que se relacionam entre si, o tempo; a atitude (ações); o espaço (lugar) e as manifestações culturais (GOMES, 2004), acabando por gerar distorções no entendimento das possibilidades deste contexto.

Vale destacar que as experiências de lazer são, habitualmente, relacionadas com o tempo que "sobra" do trabalho (aqui incluindo o tempo das aulas em escolas e em universidades; o tempo de deslocamento nos transportes: carros, trem, metrô, ônibus, entre outros; o tempo gasto quando levamos trabalho para casa). Da mesma forma, em relação aos afazeres domésticos cotidianos e as chamadas obrigações familiares (incluindo cuidar de filhos, pagar contas, limpar a casa, cuidar de animais, entre outras), aos compromissos sociais (reuniões sociais e festas como aniversários, entre outros), assim como às tarefas religiosas (incluindo orações, ida a centros espíritas ou templos 
A Dimensão Tempo na Gestão das Experiências de Lazer em Período de Pandemia da Covid-19 no Brasil Ana Paula Evaristo Guizarde Teodoro; Gustavo André Pereira de Brito; Laura Alice Rinaldi Camargo; Marcos Ruiz da Silva e Antonio Carlos Bramante

religiosos, reuniões religiosas com diversas finalidades, entre outras), além das necessidades fisiológicas (como almoçar, jantar e dormir) (DUMAZEDIER, 1973; MARCELLINO, 1987; MARCELLINO, 2002; MELO; ALVES JÚNIOR, 2003; MARINHO; PIMENTEL, 2010).

Verificou-se, finalmente, que uma considerável parcela de pessoas tem dificuldades para compreender esse tempo para o lazer, assim como identificar quais as atividades podem ser consideradas dentro dessa dimensão da vida. Esse fato parece indicar que as possibilidades de vivências neste âmbito são restritas a gostos pessoais.

\section{Considerações Finais}

Os resultados encontrados na presente pesquisa apontam quais foram as experiências de lazer das pessoas em situação de distanciamento social por conta da pandemia COVID-19, na dimensão do tempo empregado. Esses apontamentos oferecem alguns subsídios para se (re) pensar o processo de gestão das experiências de lazer, seja a partir da forma da atuação direta do profissional da área no desenvolvimento das políticas públicas de lazer, nos espaços privados, como clubes, museus, entre outros, seja no processo da autogestão, característica essencial observada entre essas pessoas dentro da casa.

Em específico sobre a influência da gestão do lazer na constituição de hábitos nas pessoas, destaca-se a autonomia como um componente imprescindível para a fruição do lazer do indivíduo. Desta forma, acredita-se que quanto mais diretiva for o processo de gestão (forma de controle, diretividade do programa ou atividade, definição do conteúdo e forma) sem a participação direta dos interessados, por exemplo, menor será sua capacidade de conquistar a autonomia. Neste caso, autonomia, neste trabalho considerada como um processo de autogestão, representada pela capacidade que o indivíduo possui 
em autorregular os diversos tempos sociais de forma equilibrada, de tal forma a permitir a fluidez das experiências de lazer.

Ao analisar a dimensão tempo na organização das experiências de lazer durante o distanciamento social por conta da pandemia COVID-19, foi possível constatar dificuldades em dimensionar esse tempo a ser conquistado para as experiências de lazer. A (re) organização da vida durante a pandemia reforçou essas dificuldades já antecipadas por Pronovost (2011) com seus estudos sobre orçamento-tempo em condições de normalidade. Elas estão associadas a alguns aspectos interligados e interdependentes, tais como, possível equívoco sobre o entendimento do que são as experiências de lazer vivenciadas dentro de casa e pela permeabilidade das funções que a vida se configura dentro de casa - o trabalho, as obrigações domésticas, a alimentação e o próprio lazer, de forma a transpassar o rigor do tempo da vida cotidiana, exterior a ela, quando em distanciamento social.

Entre os resultados da pesquisa, foi encontrada uma média diária em horas disponíveis para o lazer de 03 horas e 22 minutos de segunda a sexta-feira e de 05 horas e 08 minutos aos finais de semana. Entre os conteúdos culturais do lazer mais vivenciados, de acordo com a média diária em horas respondidas pelos participantes da pesquisa, estão: os virtuais, seguidos dos intelectuais, manuais, artísticos, turísticos, físico-esportivos e sociais. Este resultado pode corroborar com o aumento expressivo do uso da internet, no período de pandemia COVID-19, e, consequentemente, de todas as mídias que envolvem o uso das tecnologias digitais.

O equilíbrio relacionado à quantidade de horas para cada conteúdo cultural do lazer se mostrou fragilizado pelos resultados da pesquisa. A obrigação de ficar em casa, o fechamento de espaços públicos e privados, o impedimento dos contatos sociais amplos e a convivência limitada aos membros de uma mesma família, impossibilitaram formas 
tradicionais das experiências do lazer, como as festas em família, os encontros entre amigos, a utilização de ginásios e quadras para a realização de esportes coletivos e a perda significativa das possibilidades das viagens. Todas essas proibições realizadas por meio de decretos e imposições sociais, cercearam e influenciaram significativamente a liberdade de escolha das experiências fora do ambiente restrito da casa.

Por meio dos resultados apresentados no presente estudo, acredita-se que com os subsídios encontrados, os gestores que atuam no campo do lazer, podem aprimorar suas práticas profissionais ao constatar, de forma mais particular, como as pessoas compreendem a dimensão tempo para as experiências de lazer, especialmente neste período de distanciamento social, associada à sua capacidade de autogestão. Esse processo depende, em larga escala, como as pessoas são ou foram "educadas" para o lazer. Desta forma, o papel do gestor transcende as questões administrativas e avança na direção das práticas pedagógicas. O resultado do seu trabalho como educador, além de gestor, poderá provocar transformações de como as pessoas usufruem de suas experiências de lazer. O resultado dessa intervenção qualificada também como um educador poderá influenciar diretamente na escolha das experiências de lazer das pessoas quando estiverem em seus lares, seja por escolha, seja por necessidade.

As limitações do estudo podem ser expressas por meio da desigualdade na correta proporcionalidade do número de respondentes entre as várias unidades federativas do Brasil, considerando-se as possíveis diferenças regionais, assim como no recorte mais equilibrado em relação as características sócio-econômica-culturais da amostra.

Finalmente, sugere-se novos estudos que abordem esta temática, associando-os a outras dimensões do lazer, além de investigar como as organizações ligadas ao lazer públicas, privadas e do terceiro setor - se comportaram nesse período de pandemia. 


\section{REFERÊNCIAS}

ACSM, American College of Sports and Medicine, Special Communications. Quantity and Quality of Exercise for Developing and Maintaining Cardiorespiratory, Musculoskeletal, and Neuromotor Fitness in Apparently Healthy Adults: Guidance for Prescribing Exercise, 2011. Disponível em: https://00e5bba7-26f3-470c-9a5f153f4f31575a.filesusr.com/ugd/b6b1f4_74d28c6dc8a84fa5a10ec5c7707d1cb9.pdf.

Acesso em: 30 jul. 2020.

ALMEIDA, M. B. O lazer na reclusão: construção de novos modelos teóricos a partir da estruturação histórico-teórica do lazer. Lecturas: Educación Física y Deportes, Buenos Aires, ano 10, n.83, abr., $2005 . \quad$ Disponível em: https://www.efdeportes.com/efd83/lazer.htm. Acesso em: 24 jul. 2020.

AQUINO, E. M. L. et al. Medidas de distanciamento social no controle da pandemia de COVID-19: potenciais impactos e desafios no Brasil. Ciência \& Saúde Coletiva, Rio de Janeiro, v.25, supl.1, p.2423-2446, 2020.

ARGIMON, I. I. L. et al. O impacto de atividades de lazer no desenvolvimento cognitivo de idosos. Revista Brasileira de Ciências do Envelhecimento Humano, Passo Fundo, v.1, n.1, p.38-47, jan./jun., 2004.

BALSAN, R. Atividades de lazer dos idosos na cidade: um estudo de caso na cidade de Rio Claro. Geografando - Revista do Laboratório de Cartografia e Estudos Ambientais, Pelotas, v.1, n.2, p.65-87, dez., 2006.

BARDIN, L. Análise de conteúdo. Tradução de Luís Antero Reto e Augusto Pinheiro. São Paulo: Edições70, 2016.

BATISTELA, C. R.; MONTEIRO, M. Z. Autonomia em conexão com a autogestão. Revista Latino-americana de Psicologia Corporal, Recife, n.1, abr. 2014. Disponível em: http://psicorporal.emnuvens.com.br/rbpc. Acesso em: 30 jul. 2020.

BENI, M.C. Turismo e COVID-19: algumas reflexões. Rosa dos Ventos Turismo e Hospitalidade, Caxias do Sul, v.12, n.3, Especial Covid19, p.1-23, 2020. Disponível em: http://dx.doi.org/10.18226/21789061.v12i3a02. Acesso em: 02 ago. 2020.

BICUDO, M. A. V. Tempo, tempo vivido e história. Bauru: EDUSC, 2003.

BIZARRO, R. Aprender, ensinar, avaliar em F.L.E. ( $3^{\circ}$ ciclo do Ensino Básico): alguns percursos para uma autonomia. Repositório Aberto da Universidade do Porto. Porto: Universidade do Porto, Faculdade de Letras, 2004. Disponível em: https://repositorio-aberto.up.pt/bitstream/10216/8317/2/artigo8291.pdf. Acesso em 30 jul. 2020.

BRAMANTE, A. C. Lazer: concepções e significados. Licere, Belo Horizonte, v.1, n.1, p.9-17, 1998.

Professor Bramante é o entrevistado da Sexta de Aprender de julho 2020:

lazer em tempos de pandemia. Sorocaba, 24 jul. 2020a. YouTube: Fundação Luiz

licere, Belo Horizonte, v.23, n.3, set/2020. 
Almeida Marins Filho. Disponível em: https://www.youtube.com/watch?v=ZdK7L38309s\&t=2961s. Acesso em: 27 jul. 2020.

Lazer e a sua importância na vida das pessoas ontem, hoje e sempre. 31 jul. 2020b. Youtube: Panathlon Brasil. Disponível em: https://www.youtube.com/watch?v=oGtCFcaeF2k. Acesso em: 02 ago. 2020.

BRASIL. Ministério da Saúde, Secretaria de Atenção Especializada à Saúde. Departamento de Atenção Hospitalar, Domiciliar e de Urgência. Protocolo de manejo clínico da Covid-19 na Atenção Especializada, 2020a. Disponível em: https://portalarquivos.saude.gov.br/images/pdf/2020/April/14/Protocolo-de-Manejo-Clnico-para-o-Covid-19.pdf. Acesso em: 20 abr. 2020.

BRASIL. Ministério da Saúde. Portaria n⿳0356, de 11 de março de 2020, 2020 b. Disponível em: http://www.in.gov.br/en/web/dou/-/portaria-n-356-de-11-de-marco-de2020-247538346. Acesso em: 18 jul. 2020.

BRIDI, M. A.; BOHLER, F. R.; ZANONI, A. P. Relatório técnico-científico da pesquisa: $o$ trabalho remoto/home-office no contexto da pandemia COVID-19. Curitiba: UFPR, GETS, REMIR, 2020.

CALABRE, L. A arte e a cultura em tempos de pandemia: os vários vírus que nos assolam. Extraprensa, São Paulo, v.13, n.2, p.7-21, jan./jun., 2020.

CAMARGO, L. O. L. O que é lazer. São Paulo: Brasiliense, 1986.

CAMPOS, C. M. Considerações sobre a leitura em tempos de pandemia COVID 19. Editora Caminhar, Fortaleza, p.1-9, jun., 2020. Disponível em: https://www.editoracaminhar.com.br/wp-content/uploads/2020/06/ARTIGO-

Considerações-sobre-a-Leitura-em-Tempos-de-Pandemia-COVID-19-2020.pdf. Acesso em: 02 ago. 2020.

CARVALHO, F. F. B.; SILVA, R. G.; OLIVEIRA, R. B. A essencialidade das academias de ginástica para a saúde diante da pandemia da COVID-19 no Brasil. Revista Brasileira de Atividade Física \& Saúde, Florianópolis, v.25, n.1, p.1-5, 2020. Disponível em: https://www.rbafs.org.br/RBAFS/article/view/14282/11010. Acesso em: 01 ago. 2020.

COUTO, E. S.; COUTO, E. S.; CRUZ, I. M. P. \#Fiqueemcasa: educação na pandemia da COVID-19. Intefaces Científicas, Aracajú, v.8, n.3, p.200-217, 2020.

CUSHMAN, G.; VEAL, A. J.; ZUZANEK, J. (Eds.). Free time and leisure participation: international perspectives. Wallingford: CABI Publishing, 2007.

DIONISIO, M. A importância das mídias sociais durante a quarentena: redes sociais ou mídias sociais? FG - Agência de Marketing Digital, Santo André, jun., 2020. Disponível em: https://agenciafg.com.br/blog/midias-sociais-durante-a-quarentena. Acesso em: 01 ago. 2020.

DUMAZEDIER, Joffre. Valores e conteúdos culturais do lazer. São Paulo: SESC, 1980.

DUMAZEDIER, J. Lazer e cultura popular. São Paulo: Perspectiva, 1973.

licere, Belo Horizonte, v.23, n.3, set/2020. 
FISHER, K.; ROBINSON, J. Daily routines in 22 countries: diary evidence of average daily time spent in thirty activities (Technical paper). Oxford: Centre for Time Use Research, University of Oxford, 2010.

GOMES, C. L. Lazer - concepções. In: GOMES, C. L. (Org.). Dicionário crítico do lazer. Belo Horizonte: Autêntica, 2004. p.119-126.

Lazer necessidade humana e dimensão da cultura. Revista Brasileira de Estudos do Lazer, Belo Horizonte, v.1, n.1, p.3-20, jan/abr., 2014.

GONDIM, S.; BORGES, L. O. Meaningfulness and meanings of home office work: challenges for emotional regulation. In: QUEIROGA F. Home office guidelines in the COVID-19 pandemic. Brasília: SBPOT, Associação Brasileira de Psicologia Organizacional e do Trabalho, 2020. p.30-36.

IBGE. Instituto Brasileiro de Geografia e Estatística. Estimativas de população enviadas ao $2019 . \quad$ TCU. Disponível em: https://www.ibge.gov.br/estatisticas/sociais/populacao/9103-estimativas-depopulacao.html?edicao=25272\&t=resultados. Acesso em: 28 jul. 2020.

Conheça o Brasil, população, educação. 2020. Disponível em: https://educa.ibge.gov.br/jovens/conheca-o-brasil/populacao/18317-educacao.html. Acesso em: 20 jul. 2020.

LOSEKANN, R. G. C. B.; MOURÃO, H. C. Desafios do teletrabalho na pandemia COVID-19: quando o home vira office. Caderno de Administração, Maringá, v.28, ed. especial, $\quad 2020.71-75, \quad$ Disponível em: http://periodicos.uem.br/ojs/index.php/CadAdm/article/view/53637/751375150139 Acesso em: 20 jul. 2020.

LUIZ, R. R.; MAGNANINI, M. A lógica da determinação do tamanho da amostra em investigações epidemiológicas. Cadernos de Saúde Coletivo, Rio de Janeiro, v.8, n.2, p. 9-28, 2000.

MARCELlinO, N. C. Estudos do lazer: uma introdução. 3. ed. Campinas: Autores Associados, 2002.

Lazer e educação. Campinas: Papirus, 1987.

MARINHO, A.; PIMENTEL, G. G. A. Dos clássicos aos contemporâneos: revendo e conhecendo importantes categorias referentes às teorias do lazer. In: PIMENTEL, G. G. A. (Org.). Teorias do lazer. Maringá: Eduem, 2010. p.11-42.

MEDLIK, S; LOCKWOOD, A. Turismo e hospitalidade no século XXI. São Paulo: Manole, 2003.

MELO, V. A.; ALVES JÚNIOR, E. D. Introdução ao lazer. Barueri: Manole, 2003.

MELO, V. A. Conteúdos culturais. In: GOMES, C. L. (Org.). Dicionário crítico do lazer. Belo Horizonte: Autêntica, 2004. p.51-54

MUNÉ, F. Psicosociologia del tempo libre: um enfoque crítico. México: Trilhas, 1980.

licere, Belo Horizonte, v.23, n.3, set/2020. 
OLIVEIRA, A. L. A espacialidade aberta e relacional do lar: a arte de conciliar maternidade, trabalho doméstico e remoto na pandemia de COVID-19. Revista Tamoios, São Gonçalo, v.16, n.1, ed. especial, p.154-166, 2020. Disponível em: https://www.epublicacoes.uerj.br/index.php/tamoios/article/view/50448/33479. Acesso em: 20 jul. 2020.

PACHECO, R. T. B. Lazer, educação e cidadania: qual o papel da escola pública. São Paulo: Aleph, 2010.

PADILHA, V. Tempo Livre. In: GOMES, C. L. Dicionário crítico do lazer. Belo Horizonte: Autêntica, 2004. p.218-222.

PASQUALI, L. Instrumentação psicológica: Fundamentos e práticas. Porto Alegre: Artmed, 2010.

PINTO, L. M. S. M. Lazer e educação: desafios da atualidade. In: MARCELLINO, N. C. (Org.) Lazer e sociedade: múltiplas relações. Campinas: Alínea, 2008. p.45-62.

PRONOVOST, G. Introdução à sociologia do lazer. Tradução de Marcelo Gomes. São Paulo: Editora SENAC São Paulo, 2011.

RAIOL, R. A. Praticar exercícios físicos é fundamental para a saúde física e mental durante a Pandemia da COVID-19. Brazilian Journal of health Review, Curitiba, v.3, n.2, p.2804-2813, mar./abr., 2020.

REQUIXA, R. Sugestão de diretrizes para uma política nacional de lazer. São Paulo: Sesc, 1980.

; CAMARGO, L. Brazil: a new cycle of modernization. In: OLSZEWSKA, A.; ROBERTS, K. (Eds.), Leisure and lifestyle: a comparative analysis of free time. London: Sage, 1989. p.85-96.

RICARDO, L. I. C. et al. Preferências de atividades de lazer de um grupo de idosas do extremo sul do Brasil. Licere, Belo Horizonte, v.16, n.2, jun., 2013. Disponível em: https://periodicos.ufmg.br/index.php/licere/article/view/648/449. Acesso em: 02 ago. 2020. Doi: doi.org/10.35699/1981-3171.2013.648.

SCHWARTZ, G. M. O conteúdo virtual do lazer: contemporizando Dumazedier. Licere, Belo Horizonte, v.6, n.2, p.23-31, 2003.

SCHWARTZ, G. M.; et al. Educando para o lazer. Curitiba: Editora CVR, 2016.

SILVA, M. R. Lazer nos clubes sociorrecreativos. São Paulo: Factach Editora, 2009.

SOUSA JÚNIOR, J. H. et al. "\#Fiqueemcasa e cante comigo": estratégia de entretenimento musical durante a pandemia de COVID-19 no Brasil. BOCA, Boletim de Conjuntura, Boa Vista, v.2, n.4, p.72-85, 2020.

TOMAÉL, M. I.; ALCARÁ, A. R.; DI CHIARA, I. G. Das redes sociais à inovação. Ciência da Informação, Brasília, v.34, n.2, p.93-104, mai./ago., 2005. Disponível em: https://www.scielo.br/pdf/ci/v34n2/28559.pdf. Acesso em: 02 ago. 2020. 
UVINHA, R. R. et al. Leisure practices in Brazil: a national survey on education, income, and social class. World Leisure Journal, London, v.54, n.4, p.294-305, 2017.

WHO, World Health Organization. Coronavirus Disease (COVID-19) Pandemic, 2020. Disponível em: https://www.who.int/emergencies/diseases/novel-coronavirus2019. Acesso em: 20 abr. 2020.

\section{Endereço dos/as Autores/as:}

Ana Paula Evaristo Guizarde Teodoro

Rua São Celso, 71, apto 162, bloco B - Vila Domitila

São Paulo - SP - 03.626-000

Endereço eletrônico: anapaulaguizarde@yahoo.com.br

Gustavo André Pereira de Brito

Rua Praia do Bessa, 2113 - Ponta Negra

Natal - RN - 59.094-120

Endereço eletrônico: gustavo.brito@ifrn.edu.br

Laura Alice Rinaldi Camargo

Rua Alexandre Nadolny, 99, casa 10 - Santa Cândida

Curitiba - PR - 82.630-496

Endereço eletrônico: laurarinaldi@ hotmail.com

Marcos Ruiz da Silva

Rua Alexandre Nadolny, 99, casa 10 - Santa Cândida

Curitiba - PR - 82.630-496

Endereço eletrônico: mruiz4@hotmail.com

Antonio Carlos Bramante

Av. Armando Salles de Oliveira,147, apto 61 - Trujillo

Sorocaba - SP - 18.060-370

Endereço eletrônico: bramante@uol.com.br 